\title{
Wear-Model-Based Analysis of the State of Blast Furnace Hearth
}

\author{
MIKKO HELLE, HENRIK SAXÉN, BART DE GRAAFF, and \\ CORNELIS VAN DER BENT
}

The condition and state of the hearth of the blast furnace is of considerable importance since the life length of the refractories governs the campaign length of the furnace, but it is also of significance as it affects the drainage of iron and slag and the hot metal temperature and composition. The paper analyses the hearth of a blast furnace using a model of the lining wear based on the solution of an inverse heat conduction problem, studying the changes in the lining state throughout the campaign. Different operation states are detected, characterized by smooth and efficient hot metal production and by erratic behavior with large disturbances in the hearth state. During the periods of poor performance, the hearth exhibits a cycling state with stages of excessive skull growth on the unworn refractory, followed by periods of dissolution of the skull and lining erosion. An explanation of the transitions is sought by a stating and solving a force balance for the deadman with the aim to clarify whether it is floating or sitting. A connection between the thermal cycles in the hearth and the hot metal sulfur content is finally demonstrated.

https://doi.org/10.1007/s11663-021-02399-w

(C) The Author(s) 2022

\section{INTRODUCTION}

THE hearth is a crucial part of the blast furnace because its refractory lining is subjected to harsh conditions, but it cannot be repaired without a full stoppage of the furnace. ${ }^{[1]}$ As long campaign lengths are the goal, it is important to understand and possibly control the hearth conditions. The hostile conditions in the hearth make it impossible to directly measure the internal state, so it must be reconstructed based on measurements at the boundaries, i.e., the temperatures in the sidewalls and bottom. The hearth refractory is normally equipped with hundreds of thermocouples to make it possible to indirectly follow the erosion of the lining during the campaign. In the simplest form, the thermocouple signals are monitored and an alarm is issued if critical limits are exceeded. Almost 40 years ago, the first one-dimensional inverse heat conduction models were proposed ${ }^{[2]}$ to estimate the location of the hot face, and such models are still used today at many

MIKKO HELLE and HENRIK SAXÉN are with the Process and Systems Engineering Laboratory, Faculty of Science and Engineering, Abo Akademi University, Åbo 20500, Finland. Contact e-mail: henrik.saxen@abo.fi BART DE GRAAFF and CORNELIS VAN DER BENT are with the Danieli Corus, Rooswijkweg 291, $1951 \mathrm{ME}$ Velsen-Noord, The Netherlands.

Manuscript submitted July 26, 2021; accepted November 19, 2021.

Article published online January 4, 2022. plants. Acknowledging the problems of a one-dimensional treatment, two-dimensional models were later developed. ${ }^{[3-7]}$ These made it possible to appropriately describe the conditions in the region where the sidewall meets the hearth bottom. However, many models use all thermocouple information available, which gives conflicting information about the hearth wear at certain points and possibly not unique solutions. In practice, not only the wear of the lining, but also growth of build-up material, skull, may occur. Therefore, the erosion during the full campaign has to be scanned to detect the "worst case" at every location, ${ }^{[4]}$ and any decrease in the lining temperature from this point would indicate skull growth. In practice, skull may occur in some regions of the hearth simultaneously as other regions experience erosion. This calls for a systematic treatment of the problem. The analysis of the present paper applies a two-dimensional wear model ${ }^{[7]}$ based on a regularized inverse heat conduction problem to yield an overall view of the hearth wear and skull formation in three dimensions.

The work analyses thermocouple information from the hearth linings of a two-taphole blast furnace for a period of almost four years. Main periods of lining wear are detected, and the occurrences of skull formation and removal during the campaign are discussed, focusing on the extent of variations in the internal profile, possible recurring states, and whether the operation has 
managed to stabilize the lining state, which is a guarantee for a long campaign. Finally, some conclusions concerning the overall findings are drawn.

\section{MODELING}

The basis for the analysis is an inverse heat transfer model. ${ }^{[7]}$ The computational domain of the problem includes the hearth sidewall region and the hearth bottom refractory, where the heat transfer is described by the equation for heat conduction in a solid material expressed in cylindrical coordinates. The heat transfer problem is locally approximated by a static two-dimensional formulation, neglecting heat transfer in the angular $(\theta)$ direction. The temperature $T$ in the hearth lining is therefore given by a partial differential equation in two spatial coordinates, $r$ and $z$,

$$
0=\frac{1}{r} \frac{\partial}{\partial r}\left(k r \frac{\partial T}{\partial r}\right)+\frac{\partial}{\partial z}\left(k \frac{\partial T}{\partial z}\right)
$$

where $k$ is the thermal conductivity of the lining material. The two-dimensional geometry is a cross-section of the hearth at specific angles, $\theta_{i}(i=1, \ldots, K)$. The inner boundary of the geometry is the central axis of the hearth and the inner profile of the hearth lining or skull. The outer, upper, and lower boundaries are placed at positions where the boundary conditions (temperature or heat flux) can be measured or estimated, as indicated in Figure 1, where the thin dashed lines indicate the boundaries between different lining materials. At the inner wall and bottom of the hearth, a skull layer may exist, limited by the solid red and the dash-dotted blue lines in the figure, with a given thermal conductivity. The boundary conditions of the system are temperatures at the outer boundaries (B and $\mathrm{W}$ ) of the domain, extrapolated from close

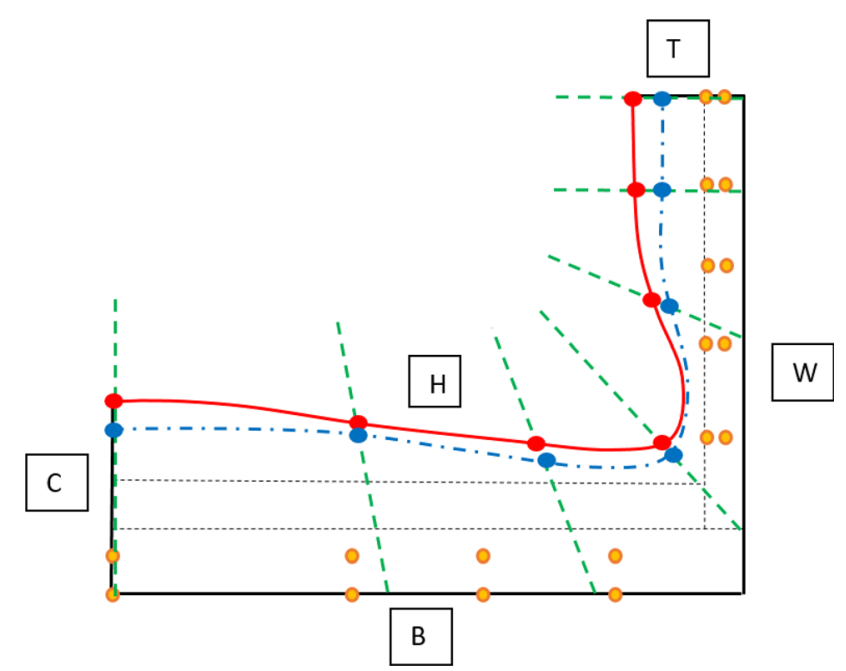

Fig. 1-Domain with external (solid black lines) and internal (red line) boundaries and thermocouples (orange solid circles). Boundary conditions are imposed at the hot face $(\mathrm{H})$, centerline $(\mathrm{C})$, bottom (B), top (T), and wall (W). The blue dash-dotted line indicates the interface between the skull and the intact lining, and the region between it and the red line represents skull (Color figure online). thermocouple pairs (depicted by orange circles). For the central axis $(C)$ and the top boundary $(T)$, zero flux is assumed.

The hearth is divided into a set of sectors and the inverse problem is solved for each sector separately. The solutions are merged to form a three-dimensional representation of the hearth. In every sector, the duplex thermocouples are labeled as inner ("reference") or outer ("boundary") to allow for an automatic and systematic treatment of the boundary conditions and the optimization problem (outlined below). The reference temperatures are used in the objective function formulation of the inverse problem to express the quality of the fit. A key issue in posing the inverse problem is to keep the number of parameters low, which will guarantee that the solution is unique. Therefore, both the skull line and erosion line (red solid and blue dash-dotted line in Figure 1) are only determined along $N$ (preset) "erosion lines", with points depicted by red and blue circles. The limited number of parameters serves to make the solution more robust and less sensitive to small changes in the measurements, which is a desired feature of an online tool.

The forward heat transfer problem is solved by the finite element method (FEM), where the heat conductivities vary with the location in accordance with the lining materials. The temperature at the hot face $\mathrm{H}$ is given (typically $1150{ }^{\circ} \mathrm{C}$ ). The objective function minimized is expressed by Eq. [2], with a term penalizing for a mismatch between the $M$ measured (superscript $m$ ) and simulated (superscript $s$ ) reference temperatures. The second term is a regularization that controls the flexibility of the curve representing the skull line through a set of smoothness parameters

$$
\min _{\mathbf{k}}\left\{\sum_{i=1}^{M}\left(T_{i}^{m}-T_{i}^{s}\right)^{2}+c \sum_{j=1}^{N} \delta_{j}^{2}\right\}
$$

The reference thermocouples $\left(T^{m}\right)$ can in principle be chosen as any (suitable) thermocouple by which the quality of the fit can be assessed, including the inner or outer of the duplex thermocouples. A detailed description of the model is provided in Reference 7.

\section{RESULTS AND DISCUSSION}

\section{A. Model Setup}

The model was applied to data from a two-taphole BF (hearth diameter $12 \mathrm{~m}$ ) spanning a period of almost four years, characterized by quite large changes in the hearth. The left panel of Figure 2 shows the lining materials setup in the model, while the right panel depicts the lines along which the lining erosion and skull are estimated. The hearth was divided into eight radial slices corresponding to sectors of equal size (45 deg). The temperatures are measured on eight levels in the simulated domain: two in the bottom and six in the wall section. A strong limitation of the measurements at the particular furnace was that there were no duplex thermocouples in the sidewall. An outer temperature 

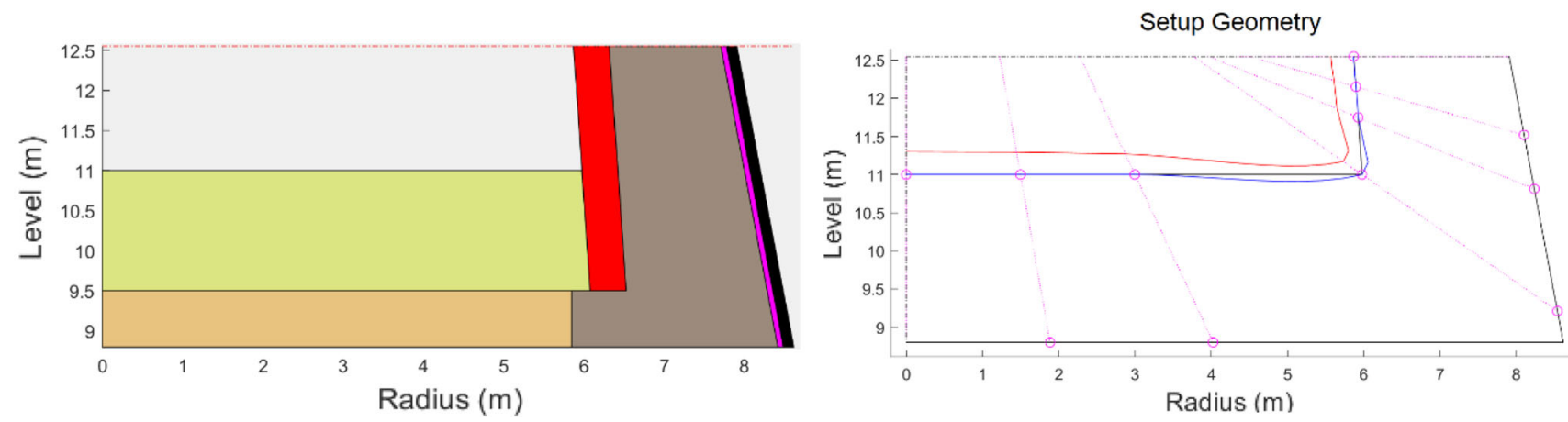

Fig. 2-Hearth design and lining materials (left) and computational lines (right). Materials: Ceramic cup, Ceramic pad, $\square$ RD-N.

was therefore artificially introduced in the model boundary (just inside the graphite layer) and by trial and error it was found that a fixed temperature of $50{ }^{\circ} \mathrm{C}$ yielded reasonable results. Daily mean values of the hearth lining thermocouple signals were used, applying thermal conductivity of $2 \mathrm{~W} /(\mathrm{m} \mathrm{K})$ to the skull layer. Even though this value is considerably smaller than the thermal conductivity of iron, values of similar magnitude have been used for the skull layer in earlier studies. ${ }^{[4,7,8]}$

\section{B. Estimated Hearth States}

The bottom panel of Figure 3 shows the estimated evolution of the hearth volume inside the skull (blue line) and inside the intact lining (green line) for the period studied. Thus, the difference between the lines represents the volume of the skull. The top panels show horizontal (left) and vertical (right) cross-sections of the estimated lining (blue) and skull (red) thickness at three moments in the first part of the period labeled $\mathbf{a}, \mathbf{b}$ and $\mathbf{c}$. The vertical cross-section is taken between the two tapholes (as indicated by the bold dashed line with a dot). The points in time where the cross-sections have been taken are shown by red dashed lines in the bottommost panel, labeled a, b and c. Studying the evolution of the volumes (bottom panel), the first 3 months of the period is characterized by quite rapid erosion, as indicated by the increase in hearth volume. During this period, the model adapts to the wear experienced earlier during the campaign, which started in 2010. After this initial period, some skull (about 20 $\mathrm{m}^{3}$ ) is formed, but from December 2015 to the end of February 2016, a thick skull layer develops on the bottom and the sidewall, as seen in the top panel which shows the state at point a. The figure reveals that the bottom has worn by almost $1 \mathrm{~m}$ and the sidewall under the tapholes shows an elephant-foot-type wear profile. Onward from point a, the sidewall skull in the taphole region gradually dissolves, followed by a rapid melting of a majority of the skull within 1 month, starting from April 10, 2016, leading to the state b. The sidewall thickness at the thinnest point (where the horizontal cross-section has been taken) is $74 \mathrm{~cm}$, which shows the progress of the elephant-foot-type erosion.
After this, a period of 10 months of uniform operation follows, where the skull volume is very stable (50 to $60 \mathrm{~m}^{3}$ ). The state on March 10, 2017, illustrated in point c, reveals a slow but still steadily progressing erosion (cf. green line, showing an increase of about $20 \mathrm{~m}^{3}$ ) in the bottom region close to the tapholes, and also a slight elephant-foot-type wear profile opposite the tapholes. However, the wear between the tapholes at the thinnest sidewall point has not progressed much (and the wall is still $70 \mathrm{~cm}$ thick). During the period between points $\mathrm{b}$ and $\mathrm{c}$, the furnace performed excellently, with high productivity, low rate of reductants, good hot metal temperature and composition and very few disturbances. This stable period is followed by an unstable state that persists: the hearth experiences skull formation followed by shorter periods (typically lasting about 1 month) where the skull melts and the hot metal clearly flows more uniformly in the hearth. A sequence of snapshots of the states at ten alternating extreme points during the period May 15, 2017-January 10, 2019, labeled (1) to, is depicted in Figure 4. The first two pairs (1 \& 2 and 3 \& (4) are seen to be very similar, where the skulled states show a quite uniform skull over the whole lining, with a somewhat thinner layer in the hearth center, while the less skulled state has some protective skull on the lining. Therefore, the erosion shows practically no progress. The pair 5 \& 6 differs from the former ones mainly by a thicker skull in the furnace center. Closer scrutiny of the profiles shows that the bottom (close to the tapholes) has eroded somewhat. The pairs $\boldsymbol{8} \& \boldsymbol{8}$ and $\boldsymbol{\theta} \&$ (1) again show very similar patterns. Thus, it may be concluded that the erosion has progressed to a state where the hearth volume and sump depth seem sufficient for preventing further (major) erosion. However, there are obvious problems in preventing substantial skull growth and promoting the flow of hot iron through the deadman, since the periods with little skull are short, and often level out at a certain inner volume $\left(250\right.$ to $\left.280 \mathrm{~m}^{3}\right)$. Thus, it seems that the deadman is prone to be (partially) choked by fines, which is likely to yield poor carburization and inappropriate drainage.

In order to analyze the process further, Figure 5 shows the progress of the skull line for five consecutive weeks, February 27, March 6, 13, 20 and 27, 2018 (before point (6) and June 1, 8, 15, 22 and 29, 2018 
a

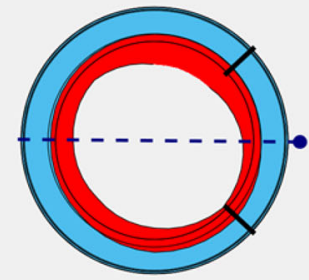

b

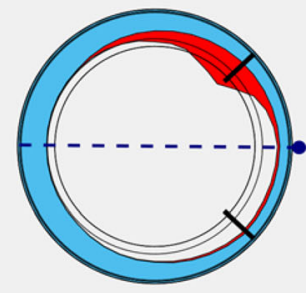

c

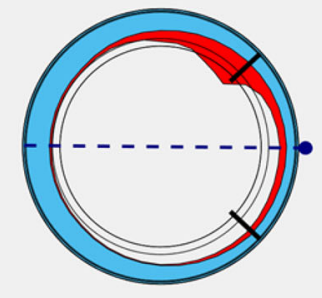

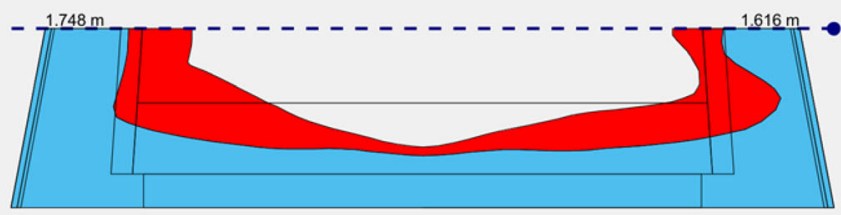
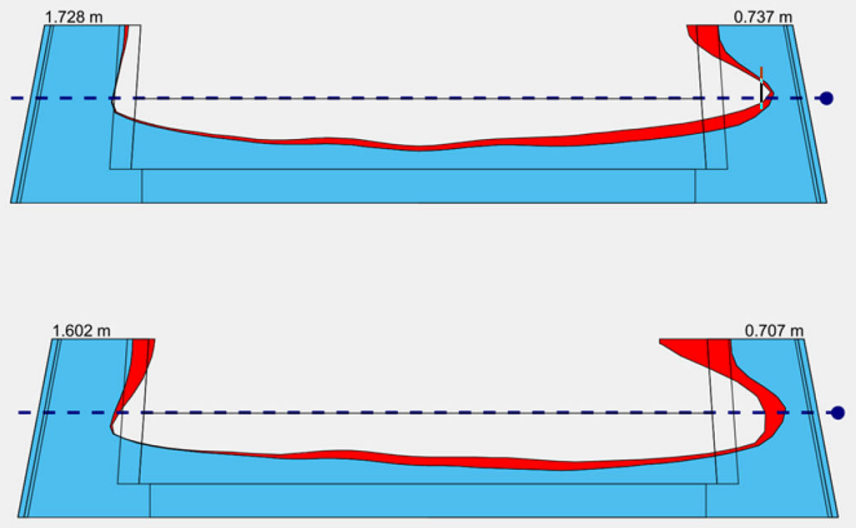

Hearth Volumes

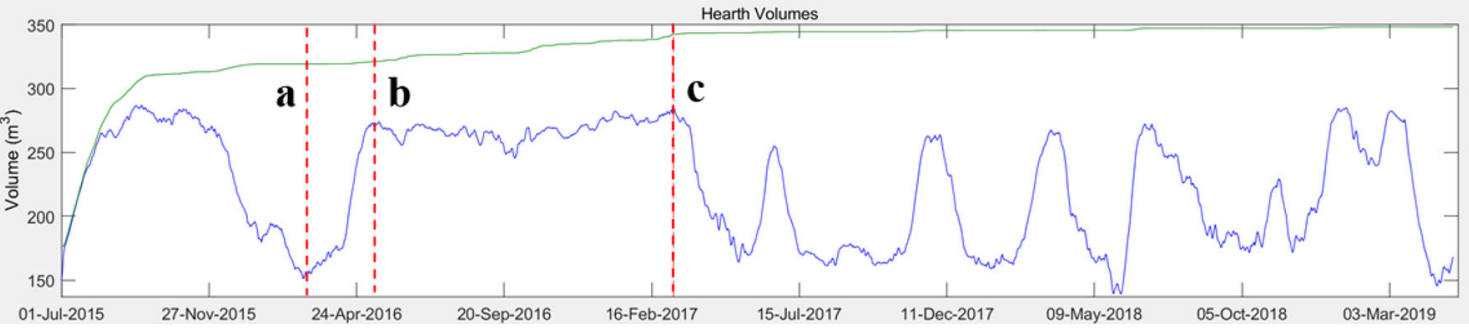

Fig. 3-Top part: Horizontal (left) and vertical (right) cross-sections of the hearth along the lines indicated by the bold black dashed line. Bottom panel: Evolution of the hearth volume inside the (red) skull (blue curve) and inside the (blue) intact lining (green curve) for the period studied estimated by the hearth wear model. Points $\mathrm{a}, \mathrm{b}$, and c represent states at the vertical dashed red lines in the bottom panel (Color figure online).

(before point 8). These two examples indicate that the skull dissolution first occurs at the tapholes (right part of the figures), forming a gutter at the joint of the sidewall and bottom that gradually spreads around the whole furnace periphery. Figure 6 shows in more detail how the changes progress in time by depicting the innermost profiles only for the days in question. Following the color sequences, the difference between the first (blue) and the second (red) profiles occurs primarily in the right part of the cross-section (i.e., at the tapholes), while the progress is more uniform later. However, close to the taphole practically no changes occur during the last 2 weeks (green $\rightarrow$ magenta $\rightarrow$ cyan), while skull keeps of melting opposite the taphole.

It is interesting to note that the general findings of the analysis of the hearth state in the BF in question show strong similarities with what has been observed for other furnaces. ${ }^{[7,9-12]}$ An example is provided in Figure 7, which shows the erosion state of a small $(7 \mathrm{~m}$ hearth diameter) BF studied in Reference 7. The behavior is occasionally strikingly similar to that seen in the second half or the period in Figure 4. For instance, during the 1.5-year period Feb. 1998-July 1999, indicated by an arrow in Figure 7, the volume inside the skull line shows spikes that extend to roughly the same inner volumes (about $40 \mathrm{~m}^{3}$, the low absolute value being due to the small furnace size and the constrained computational domain of the model). The erratic behavior of the furnace is seen to persist till the end of the studied period.

\section{Deadman Floating Analysis}

According to the estimates by the wear model, the sump depth in the BF has increased by more than $1 \mathrm{~m}$ from July 2015 to May 2019. The upper sidewall has eroded by 0.4 to $0.6 \mathrm{~m}$, while in the region of most severe erosion (at the elephant foot) about $1.5 \mathrm{~m}$ of lining is lost. The change of the sump depth increases the upward-acting buoyancy force of the iron on the submerged coke bed, expressed per area, by about $80 \mathrm{kPa}$. Furthermore, the growth in diameter favors a (partial) floating of the deadman at the edges. ${ }^{[13-15]}$ To briefly analyze whether the observed changes are reflected in the drainage of the hearth, a force 

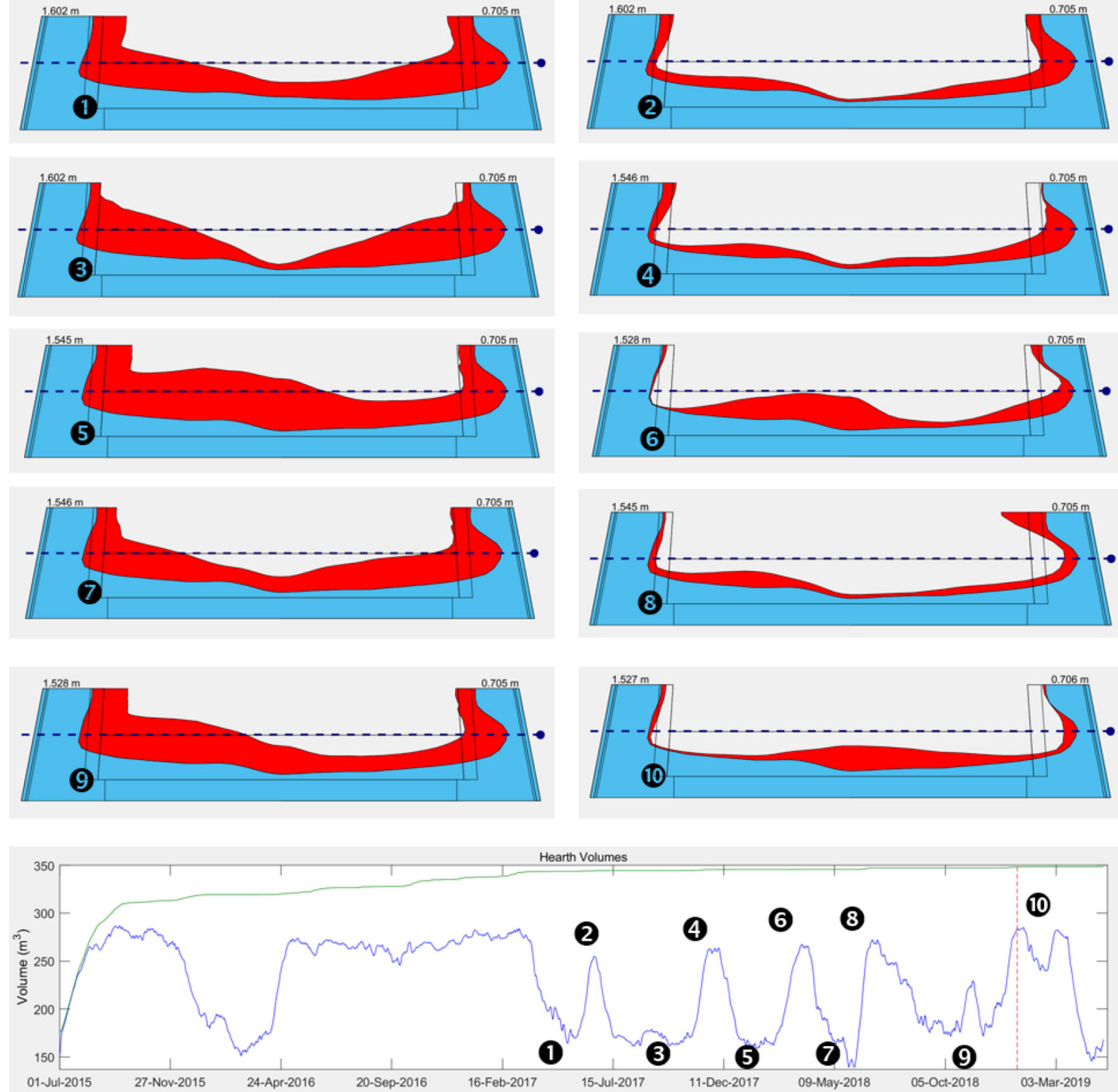

Fig. 4-Estimated hearth lining state on (1) May 15, 2017, (2 June 20, 2017, $(7$ June 1, 2018, 8 July 1, 2018, (9 Oct. 10, 2018, and (10 Jan. 10, 2019

balance was stated considering the main terms shown in Figure 8 . The downward-acting forces are caused by the weight of the burden in the lumpy zone (L), of coke and the liquid iron and slag holdup in the dribbling zone (D), and of coke below the slag level. (The weight of the cohesive zone (CZ) was not explicitly considered.) The upward-acting forces are the buoyancy of slag (S) and iron (I), and the wall friction (F) and drag of the gas $(\mathrm{G})$. Expressing these forces per cross-sectional area of the hearth, the terms in the force balance can be interpreted as pressures. Balancing the upward- and downward-acting pressures, the floating level of the deadman can be determined. If the downward-acting pressure exceeds the upward-acting one, the deadman sits on the hearth bottom.

The analysis is complicated by the fact that the downward-acting force on the deadman is not necessarily uniform in the radial direction. The literature proposes that the strong bosh gas flow from the
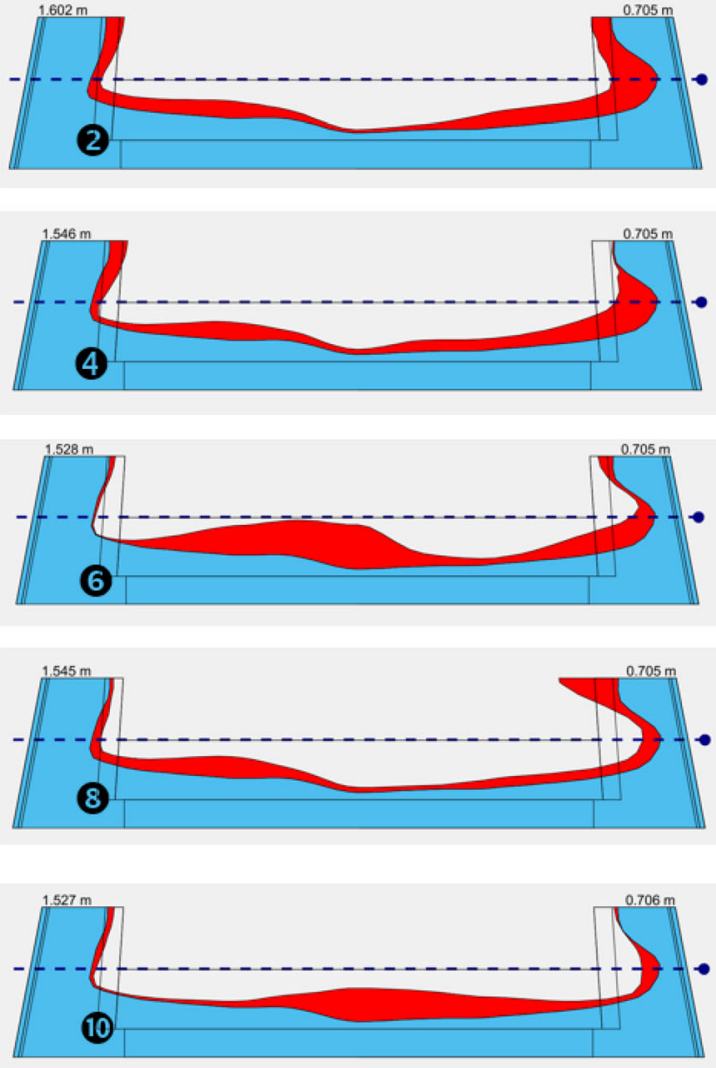

Oct. 4, 2017,

Dec. 1, 2017,

Feb 1, 2018, 6 April 1, 2018,

raceways reduces the pressure of the overlaying burden, so the downward-acting pressure under the raceways is clearly smaller than in the furnace center (see, e.g., Reference 16). This has more recently also been confirmed by CFD-DEM studies. ${ }^{[17]}$ In Reference 13, the approach was made that the maximum value of the downward-acting pressure, $p_{\mathrm{d}}^{\max }$, was determined by the overall force balance, after which the pressure on the coke bed was distributed radially by the parametric expression

$$
p_{\mathrm{d}}(r)= \begin{cases}p_{\mathrm{d}}^{\max } & \text { if } r \leq r_{0} \\ p_{\mathrm{d}}^{\max }-a\left(r-r_{0}\right)^{n} & \text { if } r>r_{0}\end{cases}
$$

where $a$ is a factor controlling the height of the (possible) coke-free layer, $n$ its shape, and $r_{0}$ the radius at the point where the downward-acting pressure starts decreasing. To simply consider the effect of the erosion and skull, the hearth was approximated to be cylindrical with a depth (cf. Figure 8) given by 

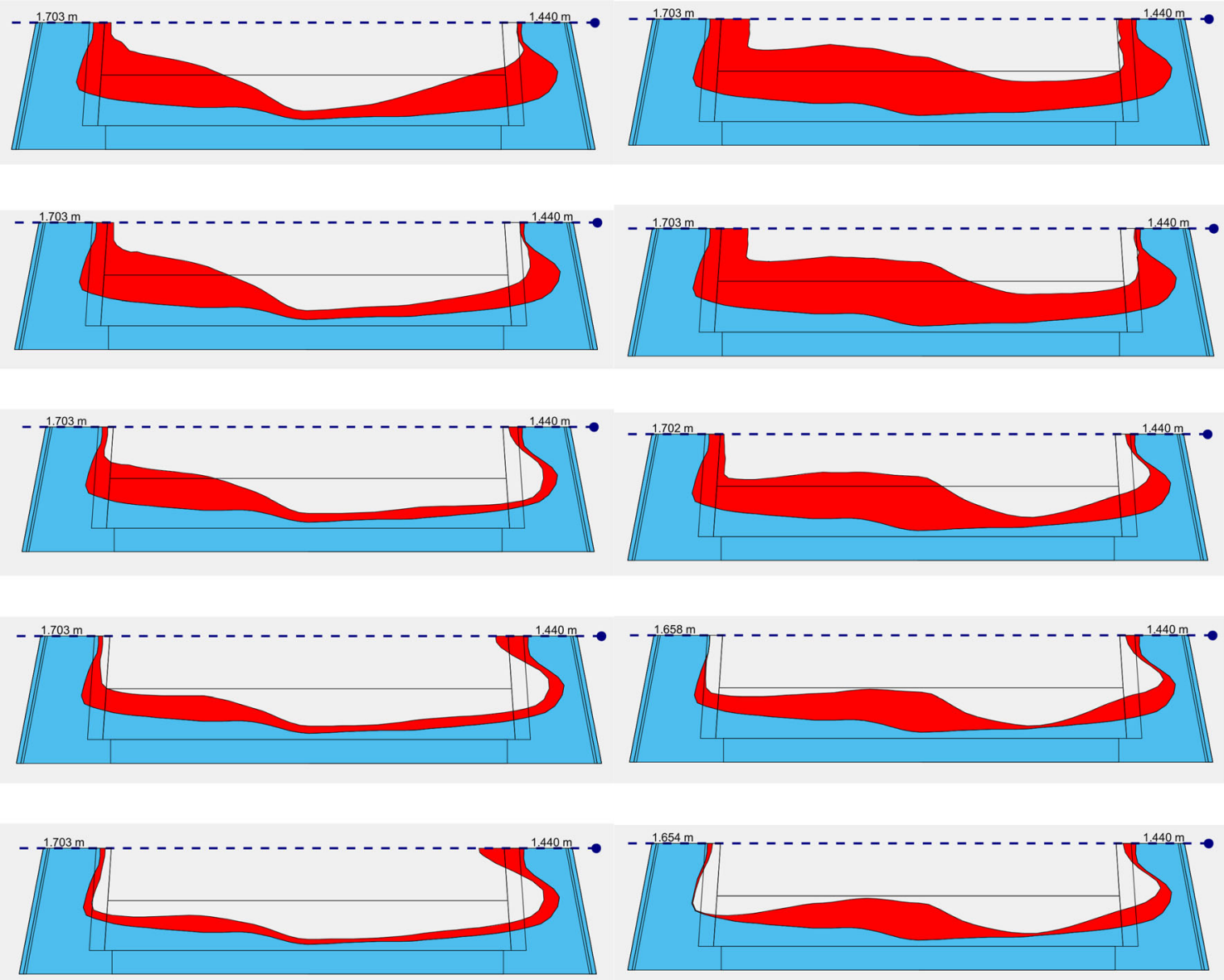

Fig. 5-Estimated hearth skull state during the dynamic transitions before points $\mathbf{6}$ and $\mathbf{8}$ in Fig. 4. Left panels: February 27, March 6, 13, 20 and 27, 2018. Right panels: June 1, 8, 15, 22 and 29, 2018.
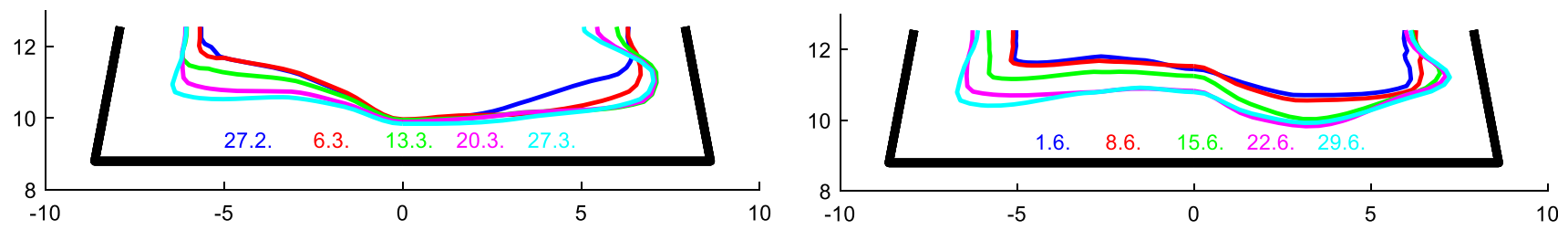

Fig. 6-Evolution of the inner profile of skull layer/refractory for the days of 2018 illustrated in Fig. 5. Colors: blue $\rightarrow$ red $\rightarrow$ green $\rightarrow$ magenta $\rightarrow$ cyan (Color figure online).

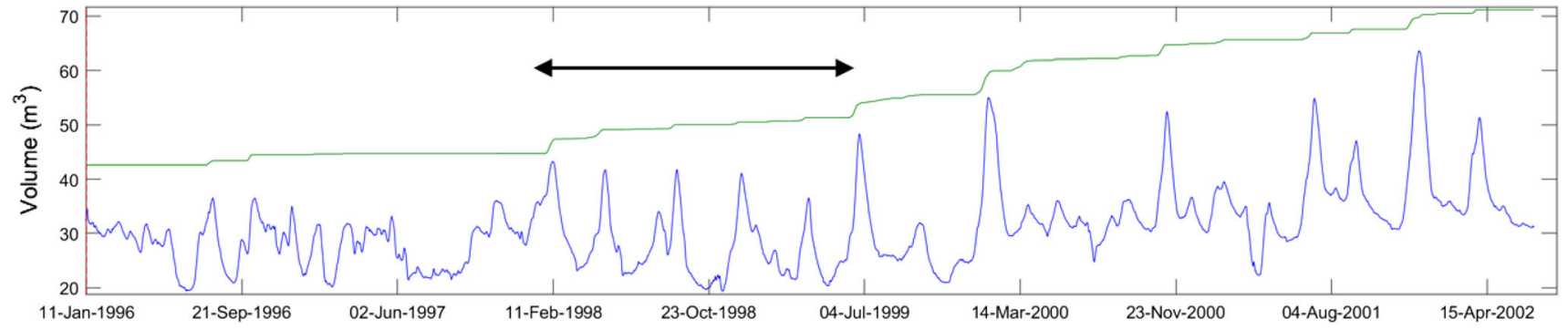

Fig. 7-Estimated volumes inside the skull (blue line) and inside the intact hearth lining (green line) for a small BF during a 6-year period. ${ }^{[7]}$ The arrow indicates a period with similar behavior as in the furnace studied in the present paper (cf. Fig. 4) (Color figure online). 


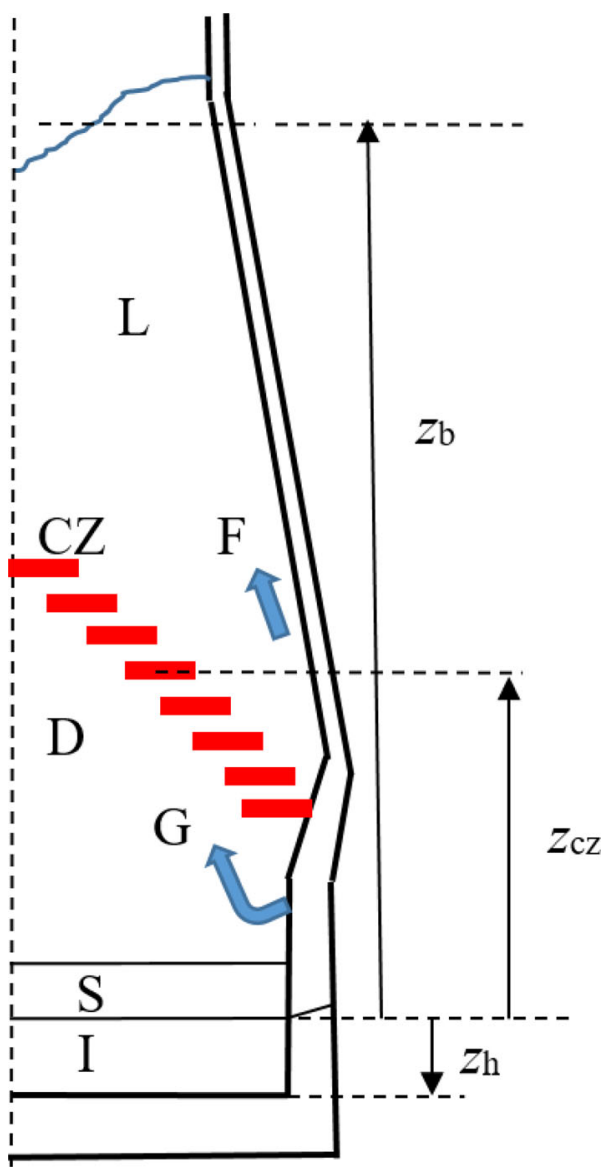

Fig. 8-Terms in the force balance equation for the deadman: lumpy zone (L), dribbling zone (D), wall friction (F), gas (G), slag (S), and iron (I). The vertical distance between the taphole and the average burden surface $\left(z_{b}\right)$, cohesive zone $\left(z_{c z}\right)$, and hearth bottom $\left(z_{h}\right)$ have also been depicted.

$$
z_{\mathrm{h}}=\frac{V_{\mathrm{scf}}}{A_{\mathrm{top}}}
$$

where $V_{\text {scf }}$ is the scull-free volume (i.e., the volume inside the skull profile, depicted by blue line in the bottom panels of Figures 3 and 4 ) and $A_{\text {top }}$ is the empty cross-sectional area at the upper domain of the region considered by the wear model.

With known pressures, the level of the deadman can be calculated during the drainage of the furnace, and the length of the iron-only period in the beginning of the tap - the so called slag delay - can be estimated computationally, if the durations of the tap and the intercast periods are known. ${ }^{[13,14]}$

Unfortunately, process data required for performing accurate force balance calculations were only available from late 2016, so the analysis had to be restricted to this period. Furthermore, due to equipment failure, no reliable records of the top pressure of the furnace was available for the period March 2017-February 2018, so the gas pressure drop over the BF had to be assumed, which affects the quality of the results of the force balance for this period of almost one year. Figure 9 shows the coke and PCI rates of the furnace for the period. The end of the very smooth and uniform period between points $\mathbf{b}$ and $\mathbf{c}$ in Figure 3 is seen to correspond to a low coke rate and a high PCI rate in the leftmost part of Figure 9. After this period, and particularly during the period of poorly controlled top pressure, the performance is seen to be worse with clearly higher coke rate and lower PCI rate. It should be noted that the three single days (within the period December 2016-February 2017) where the furnace shows unreasonably high $(>250 \mathrm{~kg} / \mathrm{thm})$ PCI rates correspond to days with long stoppages, which make the reported fuel rate inaccurate.

With reasonable assumptions concerning the average level of the cohesive zone, and neglecting wall friction, the deadman voidage and the holdup of iron and slag, the force balance model was used to estimate the slag delay. Figure 10 shows the pressure terms of the force balance, except the buoyancy term. The top panel illustrates the pressure exerted by the dry part of the bed, $\Delta p_{\text {dry }}$, i.e., the lumpy zone, while the middle panel shows the pressure of "wet" part of the bed, $\Delta p_{\text {wet }}$, including the trickling iron and slag (from the holdup) and the coke bed. (The occasional large downward spikes in $\Delta p_{\text {wet }}$ are for days with missing data and therefore no wear-model estimates.) The bottom panel depicts the pressure term, $\Delta p_{\text {gas }}$, caused by the gas drag, where the constant value in the middle represents the period where the pressure drop information was missing. It is interesting to note that all terms are of similar magnitude. These terms give $p_{\mathrm{d}}^{\max }=\Delta p_{\mathrm{dry}}+\Delta p_{\mathrm{wet}}-$ $\Delta p_{\text {gas }}$ in Eq. [3], which is the quantity that must be provided as buoyancy of the hearth liquids to induce deadman floating in the furnace center.

Figure 11 depicts the estimated hearth diameter and depth (blue and red lines in the top panel) based on the wear-model results and Eq. [4], the maximum downward-acting pressure, $p_{\mathrm{d}}^{\max }$ (middle panel), and the observed (red line) and estimated (blue line) slag delay (bottom panel). Five minutes were added to the estimated slag delay to account for dynamics of the trough and runner.

Studying the information in Figure 11, we may summarize the findings as follows: The initial part of the period is characterized by a hearth with little skull (cf. Figure 3), so both the hearth diameter and sump depth are large. The calculated downward-acting pressure varies quite substantially, mainly due to changes in the pressure drop over the bed: the period where the pressure drop was assumed constant is seen to yield a less varying (but less accurate) value of $p_{\mathrm{d}}^{\max }$. As for the slag delay, even though some of the trends in this variable have been predicted by the model, e.g., a low value in the beginning and some of the variation during the last part of the data set, large discrepancies between the model and real situation remain. The most serious mismatch occurs during the period for which the top pressure information was unavailable (March 2017-February 2018), which naturally affected the accuracy of the model. Despite the disagreements, the results of the analysis seem to indicate that the deadman is likely to 


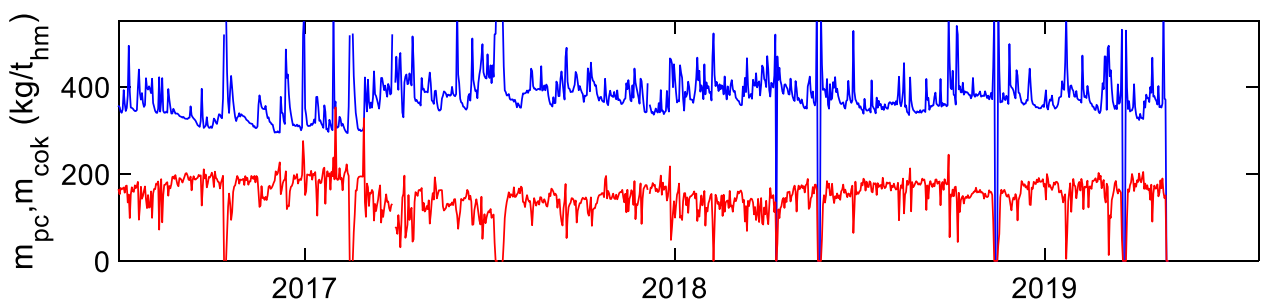

Fig. 9-Daily mean values of the coke (blue) and PCI (red) rates in the BF (Color figure online).
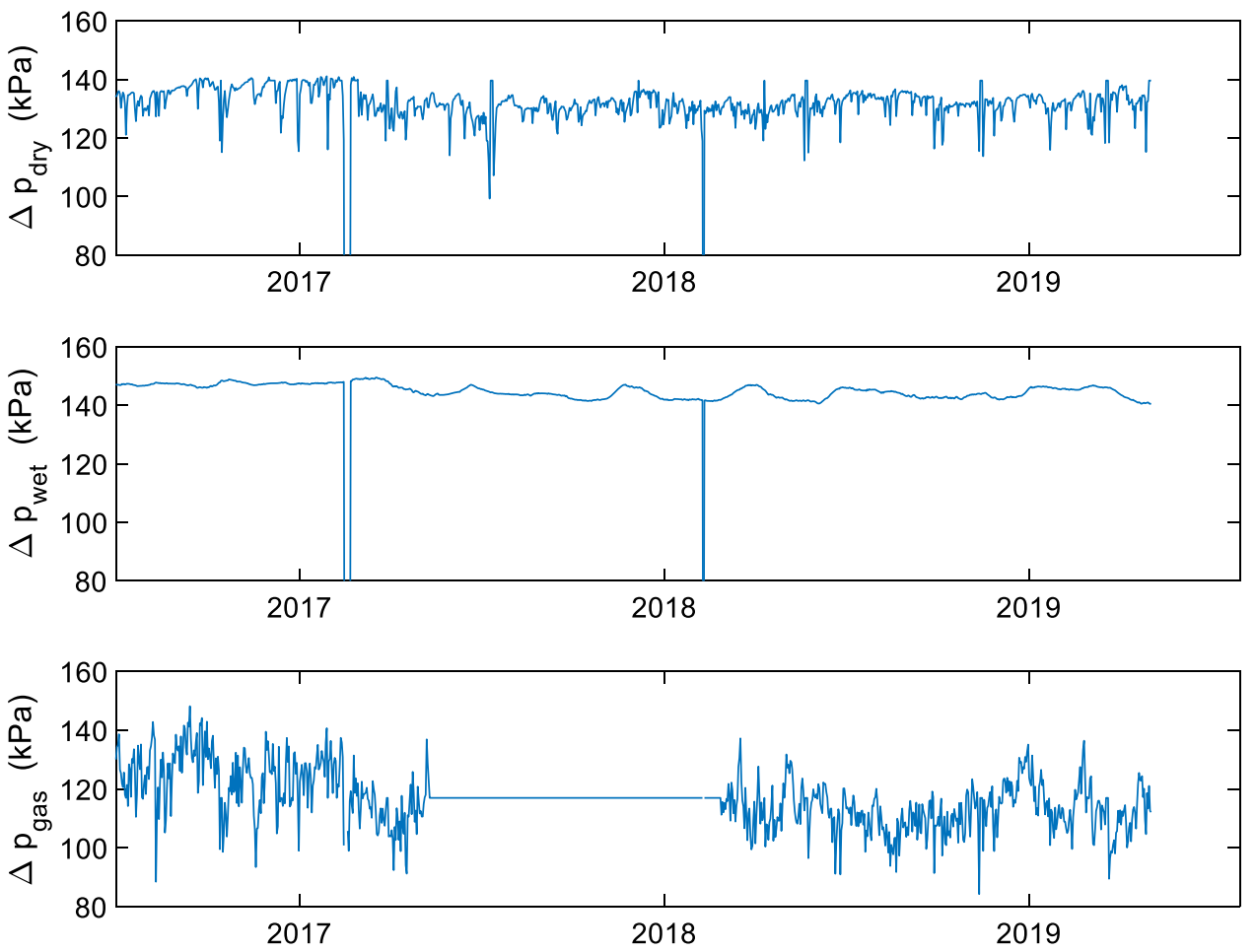

Fig. 10-Pressure exerted by the "dry" part of the bed (top panel), the "wet" part of the bed (middle panel), and by the gas (bottom panel). Information about the gas pressure drop over the furnace was not available for the period represented by the horizontal line.

float during certain periods of the campaign, characterized by a short slag delay, such as that observed during the first part of the period. Even though the hearth diameter stays large during most of the period studied, the varying sump depth may change the state of the deadman from floating to sitting. The large values of the slag delay observed and predicted for September-December 2018 and April 2019 coincide with a decrease in sump depth.

\section{Hot Metal Composition}

Supporting evidence of how the hot metal flows in the hearth can sometimes be found in the hot metal chemistry. The carbon content and the sulfur content, which are strongly negatively correlated ${ }^{[18]}$ have in several studies been found to be associated with the deadman state. A high sulfur content of the hot metal, $\underline{S}$, has been reported to indicate problems that lead to skull growth. ${ }^{[11,19]}$ However, filtering of the information is necessary before a meaningful comparison with the results of the wear model can be made, due to the inertia of the wear-model results. The tap-wise hot metal sulfur content of the blast furnace studied was therefore passed through a low-pass (Butterworth) filter of order 10 with a half power frequency of 0.03 . Due to the negative correlation, Figure 12 depicts the negative of this filtered variable, $-\mathrm{S}$ ', shifted by 4 weeks ( 28 days) ahead in time (blue line) together with the sump depth $z_{\mathrm{h}}$ (red line) estimated from the wear-model results using Eq. [4]. The time shift of 4 weeks, which was found by trial and error, thus represents the delay between the changes in the hot metal chemistry and the slower and more fundamental changes in the liquid flow paths in the deadman and the inertia of the hearth lining system interpreted by the wear model. Due to the complex phenomena in the hearth there are naturally other factors that affect the hot metal chemistry, but the overall conclusion of the findings in Figure 12 is that the sump depth and hot metal sulfur content are negatively 

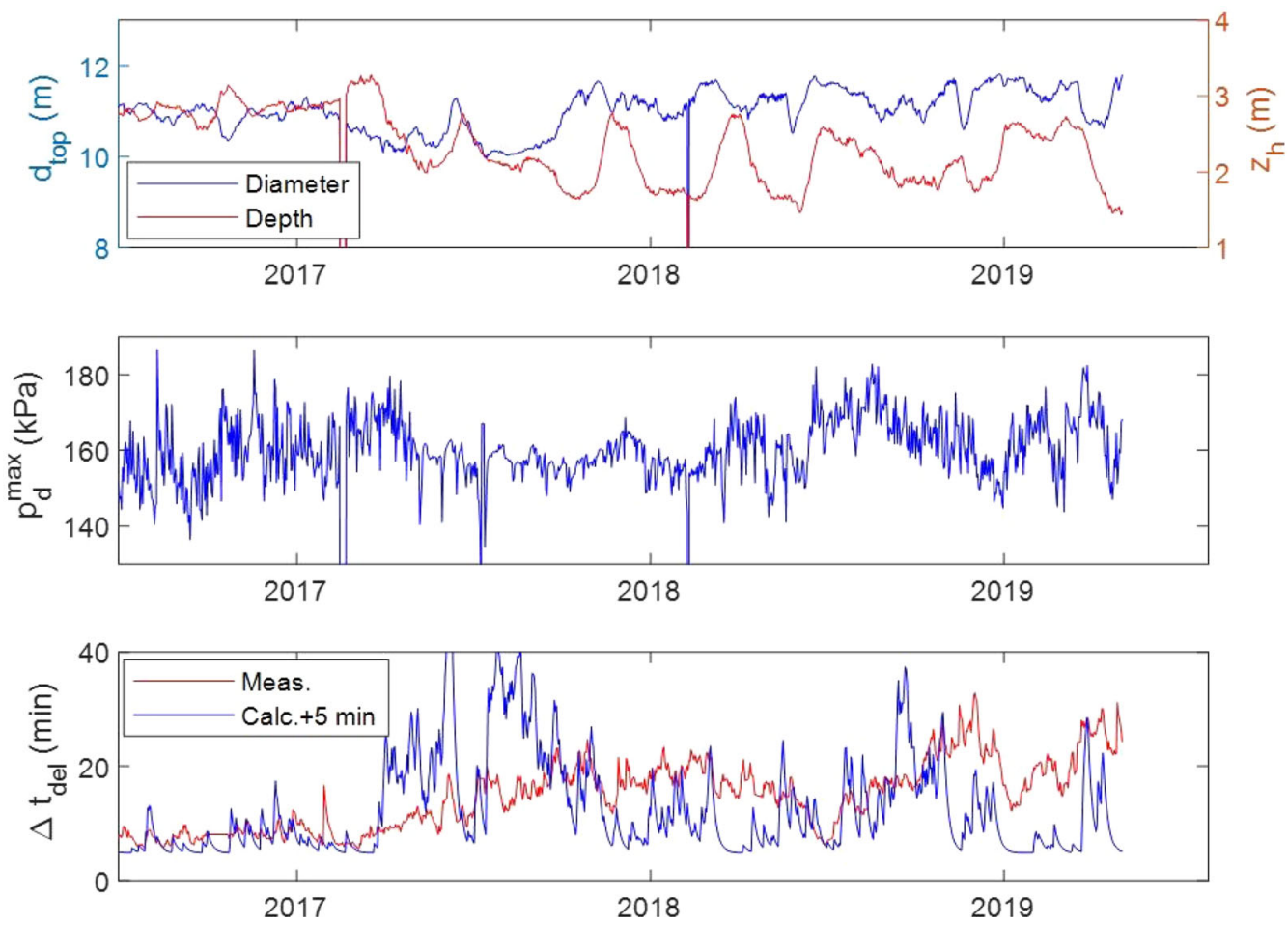

Fig. 11-Top panel: Estimated hearth diameter (blue line) and sump depth (red line). Middle panel: Downward acting pressure. Bottom panel: estimated (blue line) and observed (red line) slag delay (Color figure online).

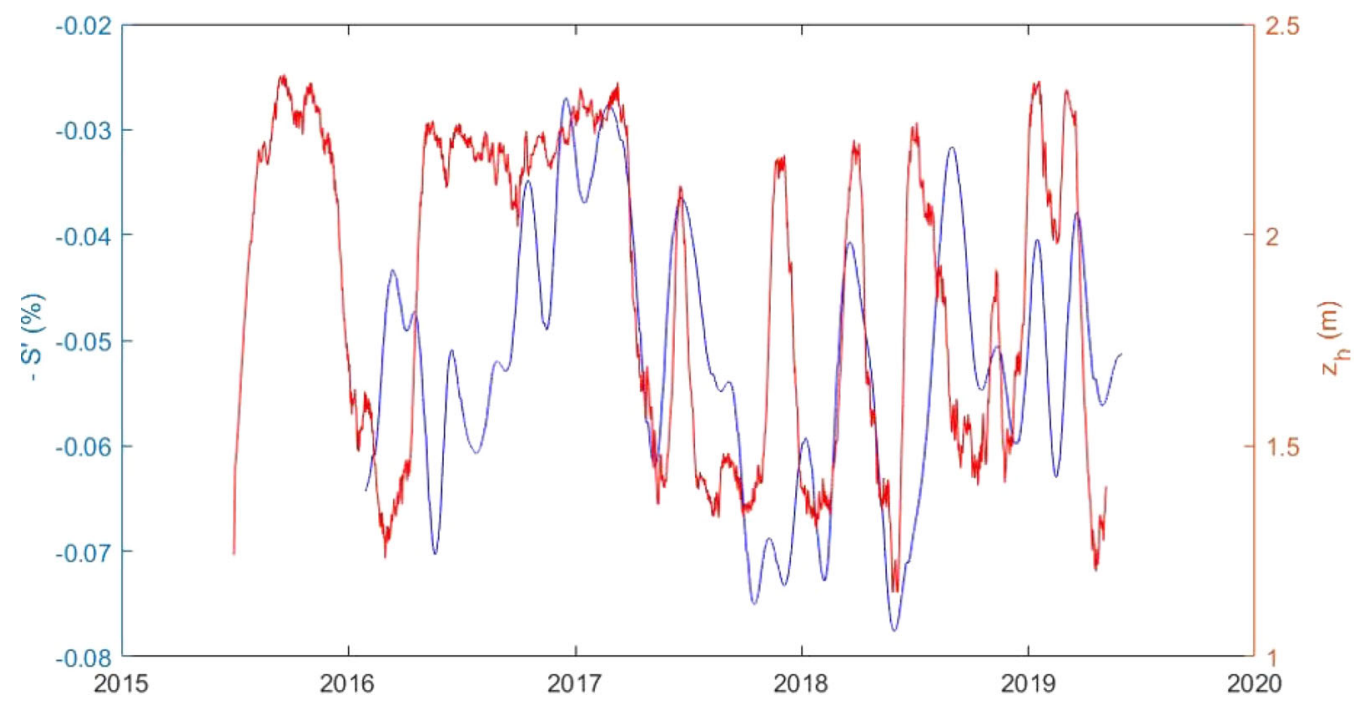

Fig. 12-Negative of the (filtered) hot metal sulfur (blue smooth line) and hearth depth (red noisy line) from the cylindrical approximation (cf. Eq. [4]) of the wear-model results (Color figure online).

correlated. A strong decrease in the sulfur content (i.e., increase in $-\underline{S}$ ') is after about a month followed by a sump depth increase, while an increase yields a corresponding decrease in sump depth. One may therefore conclude that fundamental changes in the deadman state can often be predicted by the hot metal chemistry. A possible reason for the observed behavior is that a gradual revival of an inactive deadman, where coke fines and slag of high melting point are dissolved, ${ }^{[9,20]}$ eventually leads to a hot metal flow through the core of the deadman, which consumes the bottom skull and improves the utilization of the hearth volume. However, it seems that this deadman activation within a month leads to a return to the inactive state characterized by bottom skull and high hot metal sulfur content. A theory proposed by Chapman et al. ${ }^{[21]}$ that could explain this behavior and the thermal cycles is that an inactive deadman may at some stage start floating due to the low porosity and hence large buoyancy, while the activation of the deadman, in turn, increases the 
porosity and hence decreases the buoyancy. This enforces a re-contact between the deadman and the hearth bottom, which promotes peripheral flow of the iron and gradually deactivates the core of the deadman.

\section{CONCLUSIONS}

The hearth of a two-taphole blast furnace has been studied by a two-dimensional wear model, which estimates the progress of the erosion line and the formation of build-up material ("skull") on the hearth wall and bottom. The results indicate that the hearth of the furnace experiences large variation in the rates and extents of refractory wear and skull dissolution/formation. After some initial erosion followed by a period skull formation, a time period of very efficient and smooth operation follows, with low coke rate and high PCI rate. The hearth during this period is estimated to be slowly eroding, but the refractory lining is protected by a thin skull layer. This indicates that the deadman is in a porous state and that iron can flow uniformly through it, leading to little skull in the center of the hearth bottom. After a set of unfortunate disturbances in the plant, the furnace enters a much less favorable state, where the PCI rate had to be decreased and the coke rate increases. This period, which extends to the end of the period studied, was found to be characterized by thermal cycles. Short periods where most of the skull dissolved were followed by stages with considerable skull formation. An attempt was made to shed light on this by stating and solving a force balance to assess whether the deadman was sitting or floating. Even though parts of the variations observed could not be explained by the force balance model, its results still indicated that a possible vertical motion of the deadman may be a factor that contributes to the erratic behavior. An analysis of the hot metal sulfur content revealed that this variable could often predict the formation and dissolution of bottom skull. A plausible explanation for this is that a dissolution of coke fines (and possibly slag of high melting point) leads to a gradual revival of the deadman, allowing for hot metal flow through its core and a consumption of the bottom skull. The activation of the deadman is, however, only temporary and an inactive state soon recurs, characterized by a high hot metal sulfur content. Since the reasons behind the observed behavior still remain partly unknown, further analysis of this complex system is required to pinpoint the underlying mechanisms.

\section{FUNDING}

Open access funding provided by Abo Akademi University (ABO).

\section{CONFLICT OF INTEREST}

On behalf of all authors, the corresponding author states that there is no conflict of interest.

\section{OPEN ACCESS}

This article is licensed under a Creative Commons Attribution 4.0 International License, which permits use, sharing, adaptation, distribution and reproduction in any medium or format, as long as you give appropriate credit to the original author(s) and the source, provide a link to the Creative Commons licence, and indicate if changes were made. The images or other third party material in this article are included in the article's Creative Commons licence, unless indicated otherwise in a credit line to the material. If material is not included in the article's Creative Commons licence and your intended use is not permitted by statutory regulation or exceeds the permitted use, you will need to obtain permission directly from the copyright holder. To view a copy of this licence, visit http://creativec ommons.org/licenses/by/4.0/.

\section{REFERENCES}

1. M. Geerdes, H. Toxopeus, and C. Vvd Vliet: Modern Blast Furnace Ironmaking: An Introduction, 2nd ed., IOS Press BV, Amsterdam, 2009.

2. N. Quy and C. Cripps Clark: Proc. Austral Chem. Eng. Conf., 1984, pp. 909-16.

3. M. Schulte, R. Klima, D. Ringel, and M. Voss: Stahl Eisen, 1997, vol. 117 , pp. 57-63.

4. J. Torrkulla and H. Saxén: ISIJ Int., 2000, vol. 40, pp. 438-47.

5. S. Kumar: ISIJ Int., 2005, vol. 45, pp. 1122-28.

6. M. Gonzalez and M.B. Goldschmit: Int. J. Num. Met. Eng., 2006, vol. 65 , pp. $1243-68$.

7. J. Brännbacka and H. Saxén: Ind. Eng. Chem. Res., 2008, vol. 47, pp. 7793-7801.

8. Y. Zhao, D. Fu, L.W. Lherbier, Y. Chen, C.Q. Zhou, and J.G. Grindey: Steel Res. Int., 2014, vol. 85, pp. 891-901.

9. R.J. Nightingale: The Development and Application of Hearth Voidage Estimation and Deadman Cleanliness Index for the Control of Blast Furnace Hearth Operation, PhD Thesis, University of Wollongong, Australia, 2000.

10. J. Torrkulla, J. Brännbacka, H. Saxén, and M. Waller: ISIJ Int., 2002, vol. 42, pp. 504-11.

11. K. Raipala: On Hearth Phenomena and Hot Metal Carbon Content in Blast Furnace, Doctoral thesis, Helsinki University of Technology, Finland, 2003.

12. Y. Li, S. Cheng, P. Zhang, and S. Zhou: ISIJ Int., 2015, vol. 55, pp. 2332-41.

13. J. Brännbacka, J. Torrkulla, and H. Saxén: Ironmak. Steelmak., 2005, vol. 32, pp. 479-86.

14. J. Brännbacka and H. Saxén: ISIJ Int., 2003, vol. 43, pp. 1519-27.

15. J. Brännbacka, H. Saxén, and D. Pomeroy: Metall. Mater. Trans. $B$, 2007, vol. 37B, pp. 443-50.

16. N. Tsuchiya, T. Fukutake, Y. Yamauchi, and T. Matsumoto: ISIJ Int., 1998, vol. 38, pp. 116-25.

17. F. Bambauer, S. Wirtz, V. Scherer, and H. Bartusch: Powder Technol., 2018, vol. 334, pp. 53-64.

18. A.J. Andersson, A.M.T. Andersson, and P.G. Jönsson: Ironmak. Steelmak., 2004, vol. 31, pp. 216-26.

19. M. Helle and H. Saxén: Steel Res. Int., 2008, vol. 79, pp. 671-77.

20. M. Ichida, T. Orimoto, M. Sakatani, K. Nakamura, H. Kumaoka, and H. Ueno: ISIJ Int., 2004, vol. 44, pp. 2134-43.

21. M.W. Chapman, R.J. Nightingale, and B.J. Monaghan: Influence of Coke Ash on Blast Furnace Hearth Behavior, Research Online, 1-1-2011 University of Wollongong, Australia, 2011, pp. 1-14. h ttps://ro.uow.edu.au/engpapers/1622.

Publisher's Note Springer Nature remains neutral with regard to jurisdictional claims in published maps and institutional affiliations. 